\title{
SECONDARY SCHOOL COMPUTER SCIENCE CURRICULUM: PERCEPTIONS OF STAKE HOLDERS
}

\author{
Fariha Gul* \\ Mumtaz Akhtar** \\ Mehwash Asif*
}

\begin{abstract}
Computers and information technology has become an essential part of living in current era. Developments in the field of computer science (CS) have influenced many aspects of human life including education. In order to make students skillful in this filed a subject of computer science is offered at secondary school level. Major purpose of introducing CS at secondary level was assumption that students of this age are more motivated to learn new technologies. The second reason was high dropout rate, where almost half of them enter in job market, keeping in view this trend it was necessary to develop technology literate workforce. Now as the technology has flooded in and new generation is exposed to it from birth so it is necessary to know perceptions about computer science curriculum. Major purpose of this research was to explore the perception of secondary school computer science curriculum. Population of the study includes the entire student enrolled at secondary school level in the subject of computer science curriculum their teachers and principals. The sample of the study was selected through convenient sampling and forty students ( $20=$ male, $20=$ female) took part in focus group discussion. Eight teachers and four principals were also part of the study. A focus group discussion guide was prepared to conduct discussion with students, while interview schedules were used to take data from teachers and principals. Scores of students in the subject of computer science were also taken from students and counter checked from the school administration to examine effectiveness of course. The results showed that students and teachers are not quite satisfied with current curriculum. On the other hand scores of the subject were not very high showing and loophole in effectiveness of the computer science curriculum. On the basis of results it is suggested that measures should be taken to not only improve curriculum but also for provision of physical facilities required to teach computer sciences.
\end{abstract}

Key words: computer science education, curriculum, Secondary School.

\footnotetext{
* PhD scholar, Institute of Education and Research, University of the Punjab, Lahore.

** Director, Institute of Education and Research, University of the Punjab, Lahore.
} 


\section{Introduction}

Technology has become major part of the fabric of our society as a result of it the competency in computer skill and its basic knowledge is essential (Oak, 2008). The computers have turned a significant factor in the economic deprivation or advancement of large segments of society. In current era of technology it is essential for every individual to learn use of ICT in order to survive (Adomi \& Anie, 2006). Computers are perceived as a door for becoming part of global information society as well as required skill for future workforce (Stovers, 2003). Since computing continues to have a significant impact on the world, an understanding of computer technology and its uses is important for all members of our society to be effective consumers and producers in the 21st century and beyond (McCoy, 2001). Education as system has also been effected by advances in technology. Computers are now extensively used in teaching-learning process. This has developed a new relationship between teachers and students for sharing knowledge and experience which is free from limits of time and space (Albalooshi, 2003). In this situation importance of teaching computer sciences at secondary level cannot be ignored. The schools have greater opportunity to develop computer proficiency among students so that they can meet upcoming challenges of technology world.

Computer education at secondary school level will not only create such broad public understanding but also will help to address the worldwide shortage of computer specialists. The creation of a viable computer science curriculum and its implementation at the secondary level is a necessary first step toward reaching these goals. So, the purpose of this study intends to analyze the secondary school computer science curriculum in the light of perceptions of stake holders and to suggest steps that will be needed for its purposeful implementation.

\section{Computer Education}

Computer education means gaining the know-how of the basic concepts related to a computer and the basic knowledge of computer operation. Knowledge of the basic components of a computer, the basic concepts of computer science and the know-how of some of the elementary computer applications constitutes computer education. Learning about the computer basics followed by a practical experience of using a computer is the key to computer education. Computers are widely used today, so acquiring computer skills is becoming need of all sections of the society.

Computers are not only storage devices and processing units, but also are excellent communication media. They are the means to access the internet and get connected to the world. They are also an effective audio-visual media (Oak, 2011). Computers can be used to access a vast knowledge base and search for information archives over the Internet. Only computer education can facilitate the use of computers for purposes of communication and entertainment.

The word processing applications of a computer serve as an effective means of documentation. The database management software that is a part of computer systems serve as the means of managing large amounts of data (Oak, 2011). Gaming applications and media players are some of the popular computer software, which are popularly used across the world.

The advent of e-Books, e-Zines and e-Newspapers is steadily phasing out their traditional print counterparts. The most easily available example is that of e-Bills. Many people are opting for eBills for the services they use, which are delivered straight to their e-Mail inbox and can be 
accessed anytime, anywhere. This is not only helping to save tress by decreasing consumption of printing paper, it is also convenient and time saving for both the business and the consumer.

These services and many more make owning a computer and knowing how to use it properly indispensable aspects of life in the present era.

\section{Computer Science as a Discipline in the Secondary Schools}

Comparison between computer science and other traditional technical disciplines, such as the sciences and mathematics, reveals the inclusion of advancements in several areas before including computer science as a reasonable and important subject at the secondary-school level. These are important progress indicators for providing professional recognition to the discipline and to the teachers as well. Researches indicate the following:

(1) Content standards for computer science education need to be developed and adopted, parallel to what has occurred in disciplines such as science, mathematics, the arts, etc. Curriculum frameworks aligned with these content standards can then be developed for the classroom, in conjunction with the teacher certification standards and the curriculum for teacher preparation programs.

(2) Departments of education, or other appropriate agencies, must recognize the discipline of computer science, so that the requirements for teacher certification in the discipline are established along with specific standards that must be met to receive such certification.

(3) Teacher preparation programs must be in place with a prescribed course of study in computer science and education that provide perspective teachers with the skills and knowledge to meet the standards required for a certification in the field, and to provide quality instruction in the classroom. As a relatively new discipline, especially at high-school level, provisions must be made to train or retrain teachers already in the school systems, so that they may also develop those skills and knowledge necessary to obtain such certification.

There must be a distinction between the technology and the computer science curriculum. In one perspective, computer science must be considered as subject matter and technology should be viewed as a tool that cuts across all subjects. For example, technology is used as a tool in mathematics, in science, in social science, in English, and in other disciplines, including computer science. Where the technology is the auxiliary tool in most subjects, it is the primary tool for instruction in computer science. Therefore, computer science is a subject matter and the computer is a tool and computer science is a discipline that uses it, naturally, among other tools.

Current curriculum of computer science for secondary classes (9th \& 10th) is designed according to National Curriculum Policy of Computer Science 2000 and after this no other new curriculum policy of computer science is designed for secondary classes uptill now. Grade 9 curriculum provides an introduction to computers, its components and devices, number systems, Boolean algebra, computer software and brief introduction about windows. The grade 10 course emphasizes programming, problem solving, and applications, but this analysis shown that current curriculum is not sufficient for meeting the requirements of present needs and this have been updated usually with increased density of content to reflect new developments. However, there is strong evidence (National Research Council, 1999) that a basic understanding of all these topics is now an essential ingredient to preparing high school graduates for life in the 21st century. 
Current secondary school computer science practice has, by necessity, evolved to keep pace with technology: witness the rate at which fundamentally new ideas are introduced into new products. One might suppose, then, that current computer science education has also evolved to track such new developments. However, this analysis proof that teaching of unmotivated computer science curriculum is flawed. It contributes little to the education of computer science who can acquire new knowledge as necessary, cope with dynamically changing work environments, or excel in nontraditional jobs.

Basic problem which our nation is financial problem, due to which computers and other related sources cannot be managed easily thus creating dissatisfaction among stakeholders. Now, Government of Pakistan is establishing computer labs in all the public schools but as it is in process so many schools are still without computers.

\section{Objective of the Study}

The major purpose of the study was to analyze computer science curriculum in the light of perceptions of stakeholders.

\section{Research Questions}

The study intended to answer the following questions;

1. What motivated students of secondary school to choose computer science as a subject?

2. What is perception of stakeholders about secondary school computer science curriculum in terms of its organization, presentation and usefulness?

3. Is students' learning as measured by their marks obtained in course of computer sciences up to mark?

4. Are the physical facilities available for computer science educaton at secondary school level enough?

\section{Methodology of the Study}

This study was qualitative in nature and focus group discussions along with semi-structured interviews were used to collect data. Population of the study includes all the students enrolled in the subject of computer science at secondary school level of public schools of Lahore. Sample was drawn on convenient basis and forty students were selected to participate in focus group discussion. On the other hand teachers who are teaching this subject were also part of population. Their sample was also drawn on convenient basis. Similar technique was used to select sample of principals of public schools. Focus group guide and interview schedule was developed by the researchers after literature review as instruments of the study to get the perceptions of stakeholders.

\section{Population}

Population of the study is divided into two groups; one group includes all secondary school students enrolled in the subject of computer sciences in a metropolitan city of Province Punjab. 
Second part of the population is composed of teachers who are teaching subject of computer sciences and principals of public schools. It was difficult to find total number of students enrolled in subject of computer sciences, so population of the study was derived from total number of students enrolled at secondary school level in public schools. Total number of students enrolled at secondary school level in Punjab is 4425 (Statistics Beauru of Pakistan). Each school has a single section of students enrolled in subject of computer sciences having fifty students on average. So it can be assumed that number of students making part of population is not more than one thousand approximately. However ratio of teacher does not match number of students and there are less than five hundred teachers who made part of population.

\section{Sample and Sampling Technique}

Sample of the study consisted of twenty female and twenty male students from four public schools of a metropolitan city of Pakistan. The sample was selected on convenient bases and only those students were selected whose principals allowed carrying interviews of teacher as well as focus group with students. From whole class, focus group discussion was carried out with students who volunteered to participate.

In addition to this eight teachers were also interviewed about effectiveness of secondary school science curriculum. These teachers teach to $9^{\text {th }} \& 10^{\text {th }}$ classes and have direct contact with students, so it was important to take their perception about effectiveness of computer science education. Additionally, interviews of four principals were also carried out to explore their perception about effectiveness of computer science education. Sample size is shown in following table.

Table 1

Sample of study including principals, teachers, students

\begin{tabular}{|l|l|l|l|l|l|}
\hline Schools (4) & Students & Teachers & Principals \\
\hline \multicolumn{3}{|l|}{ 9th } & \multicolumn{3}{l|}{ 10th } \\
\hline Male (2) & 20 & 10 & 10 & 4 & 2 \\
\hline $\begin{array}{l}\text { Female } \\
(2)\end{array}$ & 20 & 10 & 10 & 4 & 2 \\
\hline Total & 40 & 20 & 20 & 8 & 4 \\
\hline
\end{tabular}

The table 1 indicates spread of sample showing that total number of students who participated in study was 40 , while 8 teachers and 4 principals were also part of sample of study.

\section{Instrumentation}

Primarily two instruments were used to collect data from respondents of focus group and teachers as well. For collecting data from students a focus group guide was prepared by the researcher after literature review. It was composed on general discussion questions along with probes. This was finalized after taking expert opinion of people working in the field of curriculum.

Second instrument was interview schedule, it was semi-structured and its major focus was on exploring perceptions of teachers as well as administrators about computer science curriculum. This was validated through expert opinion. 


\section{Procedure of the study}

As first step curriculum document was analyzed to identify objectives of teaching computer science at secondary school. At the second stage, sores of students in computer science subject were taken from record office of school, in order to identify their achievement level and to evaluate the effectiveness of the existing curriculum.

At third stage focus group discussions of 40 students (20 male, 20 female) from 04 schools was carried out, each group contained 10 students from each school. Eight teachers ( $2=$ male, $2=$ female), two headmistresses and two headmasters of four schools were interviewed by using audio recorders (with due permission). Same approach was used across all groups of students. Each group discussion lasted for about one and a half hours in total.

\section{Results}

As a first step of the study the document analysis of computer science curriculum was carried out. The analysis showed following objectives of National curriculum for CS (2000) at secondary school level;

a. Enabling student to Understand primary laws, theories and concept of CS so that they can apply them as and when required

b. Enable students to develop diverse language programs of computer

c. Enabling students to appraise role of ICT and socio-economic development of the society

d. Enabling students to use internet

e. Provide strong basic concepts of CS that can help students for better learning at higher education levels

It is clear from objectives of computer science curriculum that basic purpose of introducing this subject is not only enabling students to use information technology (IT) for better future but also enable them to understand its importance at present as well as in coming years. The content of the textbook has been designed by keeping these objectives in view.

At the second stage the focus group discussion was carried out to explore perceptions of students about effectiveness of this curriculum. For this purpose a discussion, consisting of twenty students from 9th class and twenty students from 10th class was carried out in four sessions (ten participants in each session). Researcher generated discussion in order to identify their view points about the secondary school computer science curriculum.

Probing statements were developed to use as stimulator for focus group discussion. These queries started out broad, then narrowed down, and finished by focusing on the primary concern of the study. Major focus of these probes was on following five categories;

$\square$ Students' concerns

Usefulness of the course

$\square$ Presentation and organization of the course

$\square$ Physical facilities 
Focus group set-up included scheduling sessions and a diverse population of students. A varied schedule was designed for session times to allow students to find free time from academic activities. "Open hours" (e.g. times when no classes are scheduled at the school) were also included. Altogether 4 sessions were arranged with 40 students from each school. Responses of students on each category as are as follows;

\section{Students’ Concerns:}

First statement was about expectations of students while choosing computer science curriculum as an elective subject at secondary school level. About $25 \%$ of the students responded that they selected it as an elective subject because they want to get command over computer because they have interest in the use of computer. While $37 \%$ of the respondents have adopted it as they have interest in the field of IT and want to adopt it as career in future.

They were then asked about their assumption that how much of they have actually learned. Then 72 $\%$ of respondents stated that they have learned just theoretical knowledge about the computer while they have not any practical experience of it. While $16 \%$ of respondents stated that they do not have any practical experience in school, however, they use computers at home and at coaching centers. The remaining $12 \%$ indicated that they have sessions for practical implication of theoretical knowledge during - lab period\| twice a week.

\section{Usefulness of the Course}

They were then asked that whether they find this course useful or not then $73 \%$ were agree that they have learned a lot about computers. However, they also stated that this learning is limited to theory and practical knowledge is still required. $19 \%$ of the respondents agreed that they have learned theory as well as practical aspect. They claimed that due to this subject they are able to handle their own computers at home. On the other hand $06 \%$ stated that their learning is due to practice at home and coaching centers. While $2 \%$ opposed the view and stated that whatever taught is not very helpful.

They were then asked about difficulty level of the course. About $72 \%$ of the students stated that it is a difficult subject while $19 \%$ of the students found it easy. While $06 \%$ of the respondents stated that it seems difficult as they lack practice and proper learning facilities. They were then asked to specify the content that that is difficult or easy for them, and then all the students were agreed about 3, 7 and 8 chapter of 9th class computer science textbook and 7 chapter of 10th class computer science textbook. Many of 9th class students said that chapter 1, 2 and 5 are easy chapter in book and students' of 10 th class told that 1, 3 and 4th chapter are easy in computer science textbook.

From the responses of students, it was perceived by the researcher that in 9th class computer science curriculum, input/output devices, computer software and introduction to windows, these chapter were really difficult in their content and presentation but when analyst had a look on those chapters, then just one problem she found common in all those chapters that these were based on practical content and as computers were not available to the students that is why they had found them difficult otherwise those were much easy than other content. Same this problem was observed in 10th class computer science curriculum that chapter 7 which was about Microsoft word, students seems this chapter difficult because this just based on practical knowledge and this cannot be learned without the use of computer. 


\section{Presentation and organization of the Course}

In contrast when students were asked about the presentation of the content then majority of them were satisfied from it. They illustrated that the course material presented at the right speed and there is enough technical material in computer science curriculum. About the administration of the course $90 \%$ of the students were satisfied while $10 \%$ of the students comment that course administration was not efficient.

\section{Physical facilities}

The discussion then moved to availability of physical facilities. The students reported that labs are either not available or have insufficient number of working computers. Only about $15 \%$ agreed that they have appropriate computer lab for practice of theoretical knowledge, while only $20 \%$ agreed that working computers are available.

Responses of student along with themes emerged during discussion and ratio of responses is given in following table;

Table 2

\section{Results of focus group discussion}

\begin{tabular}{|c|c|c|c|c|c|c|c|}
\hline \multicolumn{2}{|c|}{ Statement 1} & \multicolumn{2}{|c|}{ Statement 2} & \multicolumn{2}{|c|}{ Statement 3} & \multicolumn{2}{|l|}{ Statement } \\
\hline Interest & $37 \%$ & $\begin{array}{l}\text { Theoretica } \\
\text { l } \\
\text { knowledge }\end{array}$ & $72 \%$ & $\begin{array}{l}\text { Organizati } \\
\text { on }\end{array}$ & $87 \%$ & $\begin{array}{l}\text { Availabilit } \\
\text { y of lab }\end{array}$ & $15 \%$ \\
\hline $\begin{array}{l}\text { Have no } \\
\text { other } \\
\text { option }\end{array}$ & $27 \%$ & $\begin{array}{l}\text { Practical } \\
\text { skills }\end{array}$ & $27 \%$ & $\begin{array}{l}\text { Presentatio } \\
\mathrm{n}\end{array}$ & $75 \%$ & $\begin{array}{l}\text { Availabilit } \\
\text { y of } \\
\text { working } \\
\text { computers }\end{array}$ & $20 \%$ \\
\hline \multicolumn{2}{|c|}{ Other reasons } & \multicolumn{2}{|l|}{$.1 \%$} & \multicolumn{2}{|c|}{ Difficulty of course } & \multicolumn{2}{|l|}{$72 \%$} \\
\hline \multicolumn{2}{|c|}{ Learning computer skills } & \multicolumn{2}{|l|}{$25 \%$} & \multicolumn{2}{|c|}{ Not very difficult } & \multicolumn{2}{|l|}{$19 \%$} \\
\hline \multicolumn{4}{|c|}{ Difficult because lack of practice } & \multicolumn{4}{|l|}{$06 \%$} \\
\hline
\end{tabular}

It is evident from the table 2 that only $37 \%$ of students elected computer sciences by their own choice and only $25 \%$ of them stated that they chose it for learning computer skills. This table also shows that $72 \%$ of the respondents stated that their learning process is focused on theoretical aspect, while only $27 \%$ stated that few skills are also taught. As a part of this questions they were also probed that whether they found course difficult or not, $72 \%$ of them perceived it as difficult, while $6 \%$ respondents claimed that it seems difficult because they lack practice.

For the third statement about organization and presentation of the course, ratio of satisfaction was very high i.e., $75 \%$ and $87 \%$. About availability of physical facilities and lab of computers sciences only $15 \%$ were agree that a working lab is available while only $20 \%$ confirmed availability of working computers.

\section{Interviews of teacher}

The teachers were interviewed for exploring their perception about effectiveness of computer science curriculum. For this purpose four female and four male teachers were interviewed from four public 
schools. These teachers teach 9th and 10 classes and were responsible for maintaining computers and labs. All of these teachers were not officially employed, but they were working as school employed on temporary contract.

About $75 \%$ of the teachers were satisfied from the quality of the curriculum and found the secondary school computer science curriculum useful. All of them were agreed that the materials and activities are written at a level appropriate for students.

When they were asked that either they are satisfied with all components of the curriculum of the computer science. About $68 \%$ of them stated that they are quite satisfied, however, few (10\%) of them were not satisfied. For example one teacher stated;

Some of the curriculum components are not useful in my view (at this level). I am not satisfied with those components like Boolean algebrall.

They were then asked that about achievement of expected students' outcomes, about $79 \%$ of teachers were not satisfied. When they were asked about reasons of failure, they stated;

There is lack of lab and other physical facilities because of those students are not getting practical knowledge. It is difficult to teach commands verballyll.

In response to the query about effect of emerging technologies on curriculum or the content of the course, one teacher commented;

Computer is a field changing day- by day so it is difficult to change curriculum every day. Practical work can be changed accordinglyll.

Teachers were satisfied (70\% of them) about the course content and found curriculum logical and well organized. But they pointed out

Examples are helpful but these can be more in some other contents were not available $\|$ and one of the teacher said - some of the lessons have inadequate informlatimal one of them told - the instructions can be more elaboratedll.

All the teachers were hopeful about the future of this subject two teachers did respond in this way, My students are not using computer yet but I hope they will enjoy itll.

When teachers were asked about the practical experience and resources of the students, they elaborate it in this way

Due to unavailability of lab my students are missing practicell.

As I visited labs I think the provision of equipment is enough for the studentsl.

When they ask about the recommendations for additional evaluation methods which would ensure student competency then they clearly discuss that current curriculum evaluation process is not satisfactory and one of them suggest evaluation procedure as;

Students evaluation is not based on the way that how they learn their lessons. So these must be some quizzes, activities to evaluate their knowledge\|. 
In response to the question about the qualifications and experience of computer science teachers all respondents were agree that required qualification for teaching at secondary school level must be sixteen years education (this is already in practice). On the other hand, one respondent elaborated it, stating;

They must have proficiency on the basis and current knowledge of computers. They should teach students in a way that they become a core computer literate. Masters or above should be the qualificationll.

Responses of teachers are given in table 3.

Table 3

Responses of teachers

\begin{tabular}{|c|c|}
\hline Themes & Percentages \\
\hline Usefulness & $68 \%$ \\
\hline Expected outcomes & $79 \%$ \\
\hline Emerging technologies & $10 \%$ \\
\hline Organization of the course & $70 \%$ \\
\hline
\end{tabular}

In is clear from the table that about $68 \%$ of the teachers were satisfied that current computer science curriculum is helpful in developing computer literacy, they were also agree (about $79 \%$ ) that expected outcomes of Computer Science (CS) curriculum can be achieved, however, it was also added that this is only possible when further facilities are provided for computer labs. They also agreed (10\% ) that emerging technologies are embedded in the curriculum, they added that as the CS is a dynamic field so its curriculum should be revised yearly. It is also clear from the table that about $70 \%$ of the respondents were satisfied about organization of the course.

\section{Interviews of principals}

As part of the study two male and two female principals/head teachers were also contacted for interviews to take their opinion about usefulness of computer science curriculum. Two of them refused plainly due to administrative tasks. Only one interview was carried out, however, after listening statements, he apologized to response as he was not teaching course, so he was unable 21 to comment. The fourth respondent given proper time interview, her responses showed her concern for growth in the field of computer science education. She has established computer center and has arranged staff for facilitating learning of students, who have chosen computer science as subject but most of them were currently not satisfied from the students' computer science results, because students achievement is low in this subject and the major reason pointed out was, just the nonavailability of the computers in the schools.

\section{Academic achievement of student}

Scores of students in the subject of computer science were also collected from respective departments of schools. The results showed that sores of students were not very high, average marks of the students in computer science subject were 25 while average maximum marks were 70 . The 
results were not satisfactory according to teachers, principals and students. However, all of them believe that this is due to lack of facilities in the field.

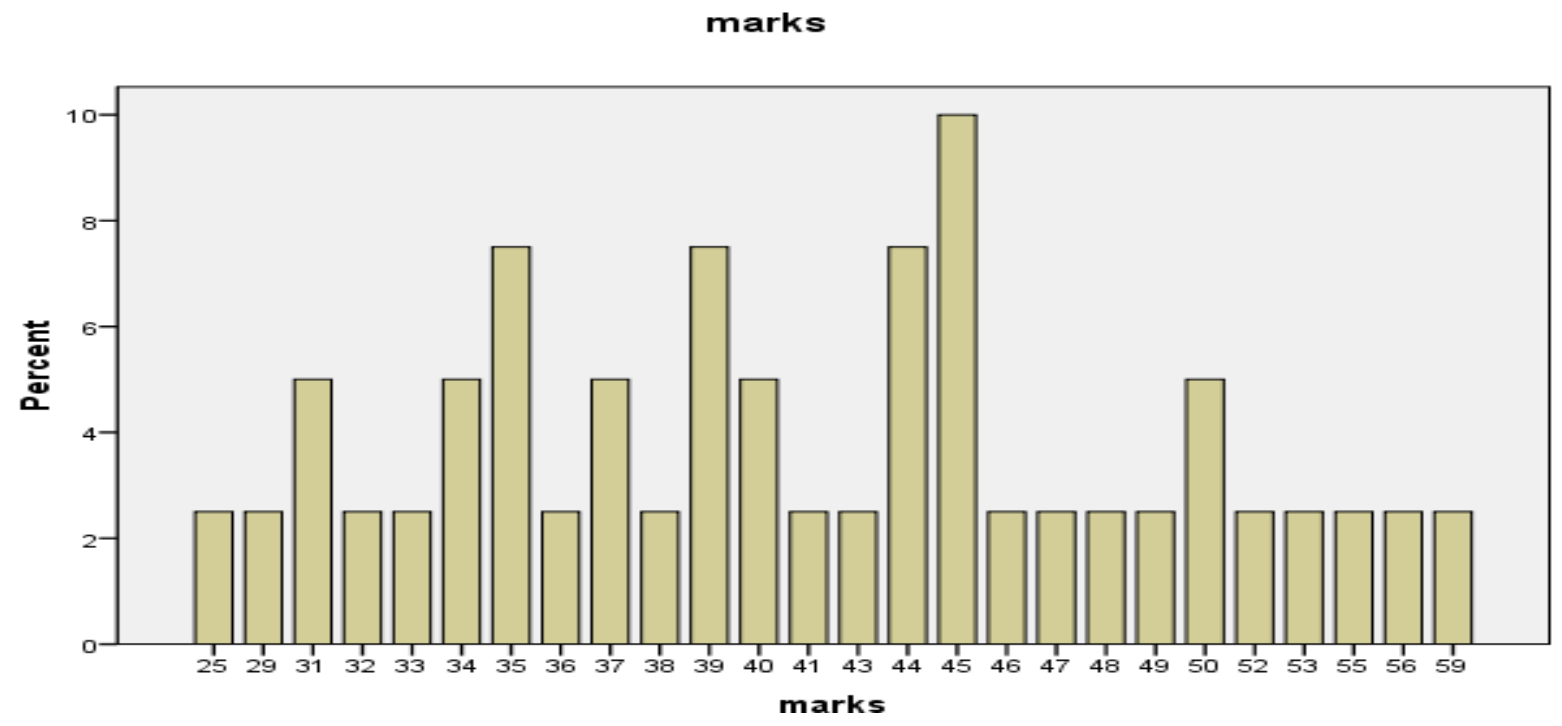

Fig.1 Graph representing spread of marks in the subject of computer sciences

\section{Conclusion and Discussion}

The results of focus group discussion with students and interviews with teachers and principals revealed that computer science curriculum is not very effective and is unable to achieve its objectives. The curriculum and its required facilities are not enough for developing appropriate skill among students. This deficiency is supported by academic scores of students in the subject to computer science.

Lack of physical facilities has profound effect on students' achievement and their satisfaction about the subject. These results are also supported by a study carried out by Shuell \& Farber (2001) stating that use of technology in class has positive impact on students learning.

The results indicated that the students having low marks are not interested in choosing CS in higher education and non availability of computer labs is a big hurdle to implement CS curriculum. According to a report of UNESCO (2005) there it is shortage of physical facilities in developing countries like Pakistan, as a result of this it is difficult to overcome challenges of IT revolution. The result is also in consensus with report of Punjab government (2013) regarding facilities of IT labs in high schools all over Punjab. This report states the government effort for providing computer facilities and IT labs in high schools all over around the Punjab and admits that although government has put much effort, however there is still need to do more.

The results also indicate that each school system has its own constraints with regard to student scheduling, availability of knowledgeable staff, and computer resources. These finding points to the need for well-designed computer science curriculum for the specifically young students, whose expectations and derived satisfaction from a computer environment are qualitatively different from many of the current options. 


\section{Recommendations}

The schools are running under serious constraints including time, budget and other socio-political issues. The recommendations are as follows:

1. Additional steps are required for formulating content standards, define professional development needs, develop curriculum (textbooks and laboratory materials), and disseminate information to students in the classroom. For all this to happen, teachers must play a substantial and leading role in the formulation of curriculum components

2. A standardized exit examination that rates IT skills, administer over a period of time, may be effective in evaluating efforts to adapt and improve a curriculum.

3. The officials should take notice of lack of availability of resources and should work on it on emergency basis.

\section{REFERENCES}

Adomi, E.E., Anie, S.O. (2006). An assessment of computer literacy skills of professionals in Nigerian university libraries. Library Hi Tech News 23 (2 ): 10- 14.

Albalooshi, F. (2003). Virtual Education Cases in Learning and Teaching Technologies, London: Irm Press 24.

Government of Pakistan (2000). National Curriculum: Computer Science Classes IX-X, Islamabad, Ministry of Education (Curriculum Wing).

Government of The Punjab (2013-14 ). Mtdf 2013-16 Development Programme. http://punjab.gov.pk/?q=system/files/ADP.pdf.

McCoy, R. (2001). Computer competencies for the 21st century information systems educator. Information Technology, Learning, and Performance Journal, 19 (2), 21-35.

UNESCO (2010). Survey of ICTs for Education in India and South Asia, Country Studies, document available on.../ict.. .education.../ict- for-education-in-south-asia.

Kimmel, H., \& Deek, F. P. (1995). Instructional technology: A tool or a panacea. Journal of Science Education and Technology, 4, 327-332.

National Research Council Committee on Information Technology Literacy. (1999). Being fluent with information technology. Washington, D.C.: National Academy Press.

Oak, Manali. (2011). Importance of Computer Education. Retrieved from http://www.buzzle.com/articles/importance-of-computer-education.html .

Economic survey of Pakistan. (2013). retrieved on 6-V06/2014 http://finance.gov.pk/survey/chapters_13/10-Education.pdf.

Stover, S. (2003). Remapping the digital divide. The Information Society, 19, 175-277. 